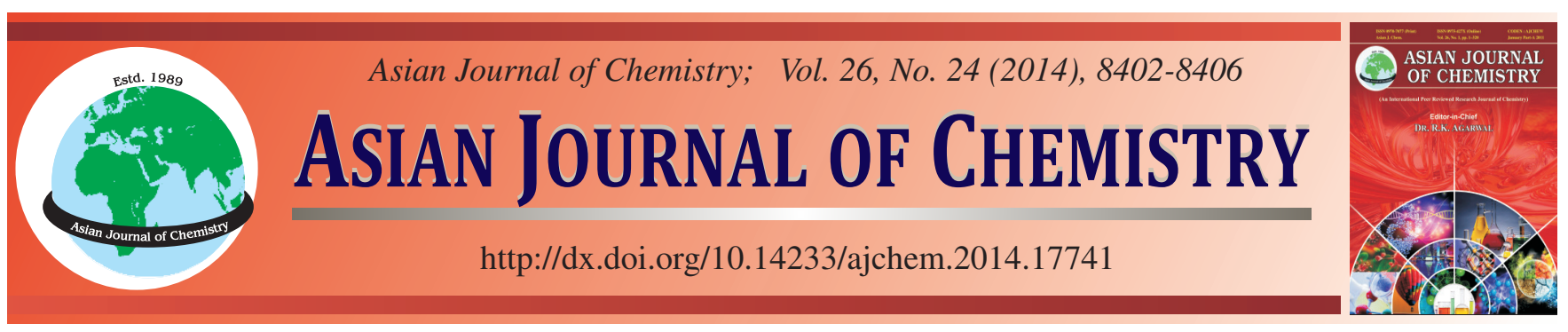

\title{
Investigation of Synthetic Musks Fragrances Pollutants in Human Breast Milk
}

\author{
S.M. YAKOUT ${ }^{1,2, *}$ and AhMED M. IsA ${ }^{3}$
}

${ }^{1}$ Biochemistry Department, College of Science, King Saud University, P.O. Box, 2455, Riyadh 11451, Kingdom of Saudi Arabia ${ }^{2}$ Hot Laboratories Centre, Atomic Energy Authority, Cairo 13759, Egypt

${ }^{3}$ Department of Obstetrics and Gynecology, King Saud University, College of Medicine, Assisted Conception Unit, P.O. 7805, Riyadh 11472, Saudi Arabia

*Corresponding author: E-mail: sobhy.yakout@gmail.com

Synthetic musks, including nitro musks and polycyclic musks are widely used in a variety of personal care and cleaning products as fragrance ingredients. Synthetic musks have been reported to be ubiquitously present in the environment and can accumulate in animal and human tissues owing to their lipophilic nature. Recently, as a result of the potential toxicity of synthetic musks observed in both in vivo and in vitro studies, human exposure to these compounds has been a great concern. Synthetic musks are detected in human maternal blood, breast milk and adipose tissue samples. Human milk is extensively used for identifying and monitoring the body burden of lipophilic and persistent environmental pollutants due to great samples volumes can be collected non-invasively compared with blood and adipose tissue. Additionally, the concentrations of organic pollutants in human milk can reflect the exposure levels of breastfed infants, as well as the contamination status of the local environment. A lot of information already exists on regulated contaminants and human health. but there is less information on the influence of the synthetic musks fragrances on human. For this reason it is presume that this work is timely due to increased interest in the last years to bridge human health with environmental contamination especially synthetic musks. The establishment of relationships between human health and levels of some of these emerging contaminants in human milk is taking place at global scale.

Keywords: Synthetic musks, Breast milk, Flame retardants.

\section{INTRODUCTION}

Anthropogenic persistent organic pollutants (POPs) are the big concern of environments due to their persistent, bioaccumulative and toxic capabilities ${ }^{1}$. These chemicals have a tendency to degrade slowly in the environment because of their resistance to biodegradation. Therefore, they are prone to biomagnification, in which they exert their toxic effects at different trophic levels and may also have extended half-lives in humans.

Among them, synthetic musks as a group of fragrance ingredients, are emerging persistent organic pollutants which have been reported to be ubiquitously present in the environment ${ }^{2}$. Synthetic musks are frequently used as alternates of natural odorous components and are extensively used in numerous consumer products including perfumes, cosmetics, detergents, shampoos, lotions, fabric softeners, fabric conditioners, cleaning agents and air fresheners ${ }^{3}$. They can be found in technical products such as fish baits, additives for cigarettes and food, herbicide formulations and explosives ${ }^{4}$.
The main classes of synthetic musks fragrances are nitro musk compounds, such as musk xylene and musk ketone and polycyclic musk compounds, including tonalide, galaxolide, celestolide, traseolide and phantolide. As a result of the toxicity of nitro musks to the environment and to human health the global production and use of nitro musks has been decreasing intensely, while the production and use of polycyclic musks, mainly tonalide and galaxolide, has been growing quickly. Polycyclic musks account for $95 \%$ of the European market and $90 \%$ of the USA market for synthetic musks ${ }^{5}$. Synthetic musks can accumulate in animal and human tissues owing to their lipophilic nature ${ }^{6}$. Due to the potential toxicity of synthetic musks observed in both in vivo and in vitro studies ${ }^{7,8}$, human exposure to these compounds has been a great concern in recent years.

There is a general agreement that human milk is the recommended diet for all babies. Human milk contains the best composition to meet their nutritional requirements in early life. Breast feeding has important protective properties against gastro-intestinal diseases and in some cases against other 
infectious diseases ${ }^{9}$. Yet, human milk-while still the best food for infants has been unintentionally compromised by unwelcome chemicals from our environment. The presence of these chemicals is the result of human activities in a technologically advanced world. However, human milk is a noble matrix often used for monitoring general population exposure to certain environmental pollutants, reflecting adult along with infant exposure through a non-invasive method of collection. So, human milk screening can yield information about the types and quantities of synthetic musks in the environment and human. Milk monitoring can also give a better understanding of our exposure to harmful environmental chemicals, which may help us to better manage such chemicals by removing or decreasing emissions or limiting their presence in the their sources.

Therefore, environmental regulators, public health officials and scientists are concerned about persistent of organic pollutants routes, their presence in our ecosystems and individuals and the relationship between exposure and adverse health outcomes. One of the outcomes of the nation's efforts is the Stockholm Convention on persistent organic pollutants in 2001. The objective of the Stockholm Convention is to protect the environment and human health from persistent organic pollutants. The Stockholm Convention is administered by the United Nations Environment Program and based in Geneva, Switzerland.

The expected outcome data will be the first survey conducted to detect synthetic musks in human milk. The results from this study will be the first to provide insight into the environmental conditions, adult burdens and historical human exposure to synthetic musks and also allow for an estimation of the dose of synthetic musks that taken by neonates via maternal feeding. Furthermore, the data will provide the basis for discussing contaminant sources, pattern and profiles in the milk. Finally, this study data will provide important information for the public health decision-makers and legislators so that more precise regulations regarding the reduction of synthetic musks emissions may be enacted.

Definition and properties of synthetic musks: Musks are organic compounds initially derived from animals or smellemitting plants to use as fragrance in home and personal care products to increase its galenic and impart pleasant odoriferous characteristics. Since of their low volatility, they are applied as fixatives, slow down the release of the fragrances from the products and helping to preserve the preferred scent of the products. The popularity of the musks as an ingredient in numerous products cause the shortage of the natural supply and the synthetic production of these compounds became inevitable. Synthetic musks are environmentally persistent chemicals. According to their physicochemical properties, musks are categorized in two main groups i.e., nitro musks and polycyclic musks that widely used in the market.
Nitromusks structure is based on aromatic carbon rings with multiple $\mathrm{NO}_{2}$-substitutes, with additional substitution by alkyl-, methoxy- or keto-groups. Musk xylene and musk ketone are the most important members of this group (Fig. 1). These compounds show musk-like odour in spite of the fact that their structure is very different from natural musk compounds. They are partially soluble in water but their relatively high octanolwater partition coefficients ${ }^{10}$ indicate high bioaccumulation potential in water biota. These compounds are also relatively persistent.
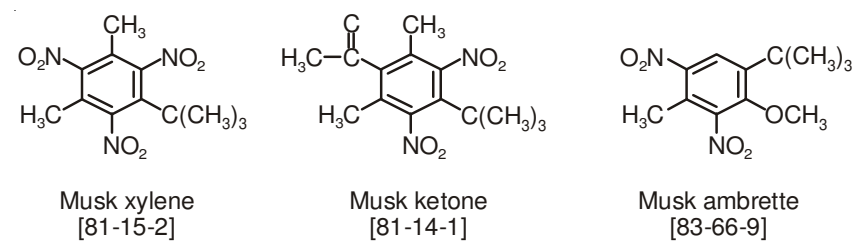<smiles>Cc1c(C)c([N+](=O)[O-])c(C(C)(C)C)c([N+](=O)[O-])c1C</smiles>

Musk tibetene [145-39-1]

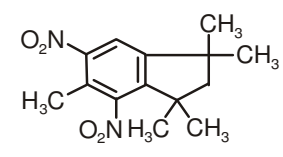

Musk moskene [116-66-5]
Fig. 1. Structural formula of the nitro musks (musk xylene and musk keton)

Polycyclic musks (Fig. 2) are another class of environmental pollutants to the great extent general population can be exposed through the use of consumer products. Polycyclic musks with numerous cycles in their structure were discovered in $1950 \mathrm{~s}^{11}$. Chemically they are indane, tetraline or coumarine derivatives and tricyclic compounds. Now, these musks are the most widely used. Galaxolide and tonalide in recent years are the most important commercial synthetic musks ${ }^{12,13}$ followed by celestolide, phantolide and traesolide. Total global use of polycyclic musks in year 2000 was approximately 4000 tons ${ }^{13}$. These compounds are more resistant against light and bases and bind well to fabric. Synthetic musks are structurally and chemically different from the natural musk compounds they are designed to replace. Their physical and chemical properties, such as vapour pressures ( $\mathrm{Vp}$ ) and $\log \mathrm{K}_{\mathrm{ow}}$ (Table-1), are more similar to those of man-made chemicals such as polychlorinated biphenyls and organochlorine pesticides, which are known to biomagnify through the food chain ${ }^{14}$.
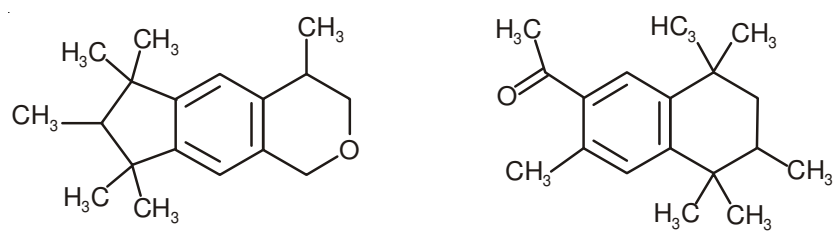

Fig. 2. Structural formula of the polycyclic musk (galaxolide and tonalide)

TABLE-1

PHYSICAL PROPERTIES OF SELECTED SYNTHETIC MUSKS

\begin{tabular}{lccccc}
\hline Compound & Abbreviation & m.w. & Solubility $(\mathrm{mg} / \mathrm{L})$ & $\log \mathrm{K}_{\mathrm{ow}}$ & Vapure pressure \\
\hline Musk xylene & MX & 297.2 & 0.15 & 4.9 & 0.00003 \\
Musk ketone & MK & 294.3 & 0.46 & 4.3 & 0.0097 \\
Galaxolide & HHCB & 258.4 & 1.75 & 5.9 & 0.073 \\
Tonalide & AHTN & 258.4 & 1.25 & 5.7 & 0.068 \\
\hline
\end{tabular}


Usage and production of synthetic musks: Synthetic musks are widely used in various consumer products such as perfumes, body lotions, soaps, shampoos, shower gels, bubble bath, facial creams, deodorants and hair products and in household products like furniture polish, laundry detergent, soaps, air fresheners and fabric softener ${ }^{5,9}$. They can also be used in food additives, cigarettes and fish bait ${ }^{8}$. Because they are economical substitutes for natural musk fragrances, the production and use of two synthetic musks, polycyclic and nitro musks, has been rapidly increasing worldwide. Global use of polycyclic musks doubled from 1987 to $2000^{14}$. This polycyclic musks increase paralleled a decrease in the use of nitro musks, which by 2000 had dropped to less than onethird compared to use in 1987. Although use of polycyclic musks appears to have declined in Europe, the same decline has not occurred in the U.S. ${ }^{15}$. Polycyclic musks and nitro musks comprise 61 and $35 \%$ in terms of production volume, respectively ${ }^{5,16}$. Tonalide and galaxolide are two of the most widely used synthetic polycyclic musks. They comprise $95 \%$ of the European market and $90 \%$ of the North American market for all polycyclic musks ${ }^{16}$.

Origin and environmental fate of synthetic musks: Synthetic musks come out into the environment through household water and wastewater. After using cleaning agents or personal care products, they are washed down to the drain and processed in treatment plants. Therefore, the main environmental contamination source for synthetic musks was through wastewater and treated wastewater discharges into receiving water bodies. Most wastewater treatment methods do not remove synthetic musks compounds. These materials end up in rivers and streams from discharge of water from sewage treatment ${ }^{17}$. The occurrence of synthetic musks in surface waters has been well documented ${ }^{11}$. Earlier studies have shown that the efficiency for galaxolide and tonalide removal in a wastewater treatment plant ranged from 63 to 88 and 64 to $89 \%$, respectively ${ }^{18}$, with the rest being discharged in the effluent typically into a surface water body. Eventually, galaxolide $(31 \mathrm{ng} / \mathrm{L})$ was detected in finished drinking water samples in the US ${ }^{19}$. Because of their lipophicity and persistence, once in the aquatic environment, synthetic musks can enter the food chain, being taken up by wildlife particularly fish and shellfish. Shellfish and fish have measurable levels of synthetic musks compounds in their tissues. In addition, some degradation products of these compounds can also be formed during wastewater treatment. These derivatives are usually less lipophilic substances, which can be easily found in aquatic environments. The main metabolite of the polycyclic musk galaxolide, the galaxolidone, was identified in natural waters ${ }^{20}$ and in fish ${ }^{21}$. Following wastewater treatment, sewage sludge is digested, dewatered and then the resulting "biosolids" are usually applied to agricultural land. Synthetic musks in the sludge that have not been degraded during digestion are therefore presented to the terrestrial ecosystem by entering the soil ${ }^{22,23}$. Due to their use in many consumer products, musks can also escape into air and dust ${ }^{24}$.

Exposure pathways of synthetic musks: Hazardous chemicals can arrive living things creature through numerous mechanisms, including swallowing, breathing and skin absorption. Once inside the body, chemicals can be excreted, metabolized, or stored in the body. Hydrophobic compounds have a tendency to accumulate in fatty tissues in phenomena called bioaccumulation. Over time, synthetic musks can bioaccumulate to concentrations far greater than that observed in the environment.

Humans can be exposed to synthetic musks through percutaneous absorption after dermal application of cosmetics, ingestion of polluted food and inhalation ${ }^{25}$. Dermal absorption is known to be main exposure pathway of synthetic musks ${ }^{25}$. Roosens et $a l .^{3}$ reported that the daily dermal exposure rates can be as high as $3.36 \mathrm{mg}$ galaxolide and $1.51 \mathrm{mg}$ tonalide for adults. Synthetic musks are lipophilic and persistent in the body, so they are expected to accumulate in lipid-rich tissues, human milk and blood.

Inhalation of musk compounds from indoor air is another exposure pathway for human beings. Indoor air is the most important environment for human exposure via inhalation. Main indoor routes of synthetic musks could be the use of liquid consumer products and spray of aerosols (e.g., air freshener). Direct leaching from fabric and textiles could also be another minor contributor to indoor musk residues. Synthetic musks in indoor air have been reported to be approximately tenfold higher than the level detected in outdoor air $^{26}$ due to the use of musks in diverse household products and their high particle-binding affinities ${ }^{27}$. Synthetic musks levels in indoor air were higher than poly chlorinated biphenyls level in households ${ }^{26}$. Consequently, indoor dust can be a major reservoir and a source for human exposure to synthetic musks ${ }^{27}$. Major musk compounds (galaxolide, tonalide, musk xylene and musk ketone) have been detected in indoor air ${ }^{28,29}$.

Exposure to synthetic musks can also occur through the diet especially fish and shellfish as the freshwater and marine ecosystems receive the greatest inputs of these compounds (from sewage and wasterwater discharges). It was speculated that fish feed could be the source of contamination of synthetic musks compounds. Previous studies have shown widespread occurrence of synthetic musks in aquatic biota including fish, crustaceans and mussels $\mathrm{s}^{30,31}$, as well as top order predators such as sharks, seals and finless porpoises ${ }^{6}$.

Toxicity of synthetic musks: Like many synthetic chemicals in everyday use, there is lack of toxicity data on synthetic musks compounds. However, it is known that synthetic musks are persistent, bioaccumulate in fatty tissue and are poorly degradable in the environment. Synthetic musks have been shown to have endocrine disrupting properties-that is, they are capable of interacting with hormone systems.

Rat and mouse studies confirmed that musk xylene and musk ketone can exhibit cogenotoxic activity due to their enzyme-inducing properties. Carcinogenic properties of these substance seen in mouse liver due to significant induction of liver enzymes ${ }^{32}$. Musk xylene is the more potent musk ketone with respect to enzyme induction properties. Musk xylene is classified as a category 3 carcinogen by the European Union and a similar classification for musk ketone is being considered $^{33}$. Musk ketone is quite similar to musk xylene with respect to physicochemical and toxicokinetic properties. Both musk ketone and musk xylene are phenobarbital like inducers of liver enzymes in both rats and mice ${ }^{34}$, there is a concern that musk ketone may be hepato carcinogenic in mice as well ${ }^{35}$. In mice, musk ketone also caused histological variations in 
the liver. Eisenhardt et $a l .{ }^{36}$ found that musk xylene and musk ketone concentration in women's blood have been correlated to several different clinical parameters of the endocrine system. With in vitro tests, musk xylene and musk ketone have been shown to be estrogenic in an assay using human breast cancer and embryonic kidney 293 cells $^{37}$.

A range of effects of polycyclic musks on different organisms have been investigated in previous studies. The inhibition of larval development in the calanoid copepod (Acartiatonsa) was associated with exposure to galaxolide and tonalide ${ }^{38}$. Their hormonal effects elicited by polycyclic musks in animals have been observed ${ }^{37}$. In addition to estrogenic activity, polycyclic musks were also have anti-estrogenic, anti-androgenic, antiprogesteronic activities and reduce the growth rate of the early stages of life, as in Lampsiliscardium, Caenor-habditiselegans, zebrafish $^{39,40}$. Like musk xylene and musk ketone, tonalide, have been shown to be estrogenic effect to human breast cancer and embryonic kidney 293 cells $^{37}$. Some dermal subchronic studies shown small liver weight increases and body weight decreases due to galaxolide exposure. oral study reported that there were signs of maternal toxicity for galaxolide with high frequency of skeletal malformations and low ossification in fetuses at the highest dose of $500 \mathrm{mg} / \mathrm{kg}$ bw/day ${ }^{41}$. Tonalide has been shown to cause acute liver damage in laboratory rodents $^{42}$. Tonalide exposure has led to clear mild hematological effects with a dark discolouration of the liver and mesenteric lymph nodes, but all effects were reversible. Finally, tonalide is listed as a photosensitizer. This due to photodegradation products results from from the interaction of tonalide and UV light ${ }^{43}$.

Regulatory position of synthetic musks: Owing to the bioaccumulative properties and health opposing reactions of nitro musks ${ }^{39}$, musk moskene, musk tibetene and musk ambrette were forbidden during the $1990 \mathrm{~s}^{44}$, while musk ketone and musk xylene still be used in cosmetics with restrictions ${ }^{17}$. Musk xylene has been on the OSPAR [Oslo-Paris Convention] list of chemicals for priority action since $1998^{45}$. In 2011, the European Commission stated its decision to ban musk xylene under the new European Chemicals Legislation-Registration, Evaluation, Authorisation and Restriction of Chemicals $(\mathrm{REACH})$, bringing European Union guidelines in line with the worldwide International Fragrance Association (IFRA) Standards. This ban was paralleled by an increasing use of polycyclic musks, with numerous high volume use products, such as tonalide and galaxolide. Lately European Union Scientific Committee on Cosmetic Products and Non Food Products, advises that galaxolide can be used as a fragrance ingredient in cosmetics without limitations and that tonalide can be used up to a maximum of $12 \%$ of the fragrance compound. Although polycyclic musks have been tested in the past and showed no toxicological and dermatological effects ${ }^{12}$, their great use, its chemical stability and low biodegradability ${ }^{12}$ led to their steady replacement by $3^{\text {rd }}$ group of fragrances, the macro cyclic musks. Though little information available on macrocyclicmusks these compounds seem to be more environmentally kind. OSPAR recommend that macrocyclicmusks may be acceptable alternates, however assessment of their environmental profile is needed ${ }^{45}$.

Studies on synthetic musks in human milk: Human breast milk is widely used for finding the body burden of lipophilic and persistent environmental contaminates as it can be got non-invasively in large amounts compared with adipose tissue and blood. Also, contaminates level in breast milk can provide exposure data about the mother and breastfed infant, as well as the local pollution status ${ }^{46}$. The lipophilic contaminates concentration in breast milk can be associated to their concentration in serum, plasma and adipose tissue, reflecting the body burden of these contaminants ${ }^{47}$. Therefore, breast milk has been used to assess the degree of human exposure to synthetic musks in many countries.

Some European countries, such as Sweden and Germany, have been regularly screening the concentrations of synthetic musks in breast milk for many years ${ }^{48}$. Different concentration in breast milk samples have been found in different regions (Table-2), such as the United States, Denmark, Sweden and Korea $^{16,49,50}$. In general, polycyclic musks are detected more

\begin{tabular}{|c|c|c|c|c|c|}
\hline \multicolumn{6}{|c|}{$\begin{array}{c}\text { TABLE-2 } \\
\text { STUDIES ON SYNTHETIC MUSKS IN HUMAN MILK [Ref. 44] }\end{array}$} \\
\hline MS & Country & Population & Concentrations & Frequency $(\%)$ & Ref. \\
\hline Galaxolide & China & 10 & Range $12-68 \mathrm{ng} / \mathrm{g}$ lw & 100 & 52 \\
\hline Galaxolide & China & 100 & Median 63 ng/g lw & 99 & 54 \\
\hline Galaxolide & Switzerland & 54 & Range $6.1-310$, median $36 \mathrm{ng} / \mathrm{g}$ lw & 83 & 51 \\
\hline Galaxolide & South Korea & 20 & Range $0.06-0.52$ & 100 & 49 \\
\hline Galaxolide & USA & 31 & Median 136 ng/g lw & 97 & 16 \\
\hline Tonalide & China & 10 & Range $23-118 \mathrm{ng} / \mathrm{g}$ lw & 100 & 52 \\
\hline Tonalide & China & 100 & Median $5 \mathrm{ng} / \mathrm{g} \mathrm{lw}$ & 75 & 54 \\
\hline Tonalide & Switzerland & 54 & Range $4.8-28.8$, median $10.2 \mathrm{ng} / \mathrm{g} \mathrm{lw}$ & 13 & 51 \\
\hline Tonalide & South Korea & 20 & Range $0.02-0.09 \mathrm{ng} / \mathrm{g} \mathrm{lw}$ & 65 & 49 \\
\hline Tonalide & USA & 31 & Median $53 \mathrm{ng} / \mathrm{g}$ lw & 56 & 16 \\
\hline Musk ketone & China & 10 & $<$ LOQ & 60 & 52 \\
\hline Musk ketone & China & 100 & Median $4 \mathrm{ng} / \mathrm{g}$ lw & 60 & 54 \\
\hline Musk ketone & Switzerland & 54 & Range $0.25-12.0$, median $0.64 \mathrm{ng} / \mathrm{g}$ lw & 63 & 51 \\
\hline Musk ketone & South Korea & 20 & Range $0.02-0.22 \mathrm{ng} / \mathrm{g} \mathrm{lw}$ & 53 & 49 \\
\hline Musk ketone & USA & 31 & Median $58 \mathrm{ng} / \mathrm{g}$ lw & 85 & 16 \\
\hline Musk xylene & China & 100 & Median 17 ng/g lw & 83 & 54 \\
\hline Musk xylene & Switzerland & 54 & Range $0.25-31.6$, median $1.34 \mathrm{ng} / \mathrm{g}$ lw & 87 & 51 \\
\hline Musk xylene & South Korea & 20 & Range $0.02-0.15 \mathrm{ng} / \mathrm{g} 1 \mathrm{w}$ & 65 & 49 \\
\hline Musk xylene & USA & 31 & Median $17 \mathrm{ng} / \mathrm{g}$ lw & 36 & 16 \\
\hline
\end{tabular}


frequently and at higher concentrations than nitro musks in Europe $^{50,51}$. An identical trend is observed for US breast milk ${ }^{16}$. Increasing galaxolide concentrations and decreasing musk xylene/musk ketone concentrations in breast milk was observed. Concentrations of musk ketone were lower than the quantification limit (Table-2). This outline parallels with the greater production and usage of galaxolide, compared to other synthetic musks (187). Significant decreasing of tonalide/musk xylene concentrations and stable galaxolide concentrations in Swedish breast milk during 1996 to 2003, were reported ${ }^{50,16}$. A down trend regarding musk xylene is likely, since the industry has voluntarily replaced the nitro musks with polycyclic musks ${ }^{17}$. This reduction has also been observed in human serum studies. Kang et al. ${ }^{49}$ observed lower concentrations in breast milk than in serum and slight association in concentrations among maternal serum, umbilical serum and breast milk. However, women with a high use of perfume during pregnancy had elevated milk concentrations of galaxolide and elevated concentrations of tonalide were observed among women reporting use of perfumed laundry detergent, which strongly suggests that perfumed products are important sources of musk exposure both among the mothers and the nursed infants ${ }^{50}$.

A few studies have reported musk level in China and regional differences in musk distributions were proposed, while information on the temporal trend of musks in human breast milk is not available ${ }^{52,53}$.

\section{ACKNOWLEDGEMENTS}

The authors would like to extend their sincere appreciation to the Deanship of Scientific Research at King Saud University for its funding of this research through the Research Group Project No RGP-VPP-184.

\section{REFERENCES}

1. R.J. Law, C.R. Allchin, J. de Boer, A. Covaci, D. Herzke, P. Lepom, S Morris, J. Tronczynski and C.A. de Wit, Chemosphere, 64, 187 (2006).

2. R. Guo, I.-S. Lee, U.-J. Kim and J.-E. Oh, Sci. Total Environ., 408, 1634 (2010).

3. L. Roosens, A. Covaci and H. Neels, Chemosphere, 69, 1540 (2007).

4. U. Klaschka and M. Kolossa-Gehring, Environ. Sci. Pollut. Res. Int., 14(Suppl 1), 44 (2007).

5. J.L. Reiner and K. Kannan, Chemosphere, 62, 867 (2006).

6. H. Nakata, Environ. Sci. Technol., 39, 3430 (2005).

7. R.H.M.M. Schreurs, M.E. Quaedackers, W. Seinen and B. van der Burg, Toxicol. Appl. Pharmacol., 183, 1 (2002).

8. D. Salvito, Environ. Health Perspect., 113, A802 (2005).

9. B. Rebhan, M. Kohlhuber, U. Schwegler, B.V. Koletzko and H. Fromme, J. Pediatr. Gastroenterol. Nutr., 49, 467 (2009).

10. K.-W. Schramm, A. Kaune, B. Beck, W. Thumm, A. Behechti, A. Kettrup and P. Nickolova, Water Res., 30, 2247 (1996).

11. G. Rimkus, Synthetic Musk Fragrances in the Environment, SpringerVerlag, Berlin-Hei-Delberg-New York, New York (2004).

12. T. Luckenbach and D. Epel, Environ. Health Perspect., 113, 17 (2004).

13. S. Tanabe, Mar. Pollut. Bull., 50, 1025 (2005).

14. A.M. Peck and K.C. Hornbuckle, Environ. Sci. Technol., 38, 367 (2004).

15. IFRA Standard $47^{\text {th }}$ Amendment, Available online (2013).

16. J.L. Reiner, C.M. Wong, K.F. Arcaro and K. Kannan, Environ. Sci. Technol., 41, 3815 (2007).

17. G.G. Rimkus, Toxicol. Lett., 111, 37 (1999).

18. Z. Hu, Y. Shi, S. Zhang, H. Niu and Y. Cai, Bull. Environ. Contam. Toxicol., 86, 302 (2011).

19. M.J. Benotti, R.A. Trenholm, B.J. Vanderford, J.C. Holady, B.D. Stanford and S.A. Snyder, Environ. Sci. Technol., 43, 597 (2009).

20. K. Bester, J. Environ. Monit, 7, 43 (2005).
21. R. Kallenborn, R. Gatermann, T. Nygard, J. Knutzen and M. Schlabach, Fresenius Environ. Bull., 10, 832 (2001).

22. A.M. DiFrancesco, P.C. Chiu, L.J. Standley, H.E. Allen and D.T. Salvito, Environ. Sci. Technol., 38, 194 (2004).

23. J.L. Stevens, G.L. Northcott, G.A. Stern, G.T. Tomy and K.C. Jones, Environ. Sci. Technol., 37, 462 (2003).

24. H. Fromme, T. Lahrz, M. Piloty, H. Gebhart, A. Oddoy and H. Ruden, Indoor Air, 14, 188 (2004).

25. S. Muller, P. Schmid and C. Schlatter, Chemosphere, 33, 17 (1996).

26. R. Kallenborn and R. Gatermann, Synthetic Musks in Ambient and Indoor Air, In: Handbook of Environmental Chemistry, Spring Heidelberg, p. 85-104 (2004).

27. B. Werner, Synthetic Musks in House Dust, In: Handbook of Environmental Chemistry, Springer, Heidelberg, p. 105-121 (2004).

28. D. Chen, X. Zeng, Y. Sheng, X. Bi, H. Gui, G. Sheng and J. Fu, Chemosphere, 66, 252 (2007).

29. J. Regueiro, C. Garcia-Jares, M. Llompart, J.P. Lamas and R. Cela, J. Chromatogr. A, 1216, 2805 (2009).

30. K. Kannan, J.L. Reiner, S.H. Yun, E.E. Perrotta, L. Tao, B. JohnsonRestrepo and B.D. Rodan, Chemosphere, 61, 693 (2005).

31. Y. Wan, Q. Wei, J. Hu, X. Jin, Z. Zhang, H. Zhen and J. Liu, Environ. Sci. Technol., 41, 424 (2007).

32. S. Apostolidis, T. Chandra, I. Demirhan, J. Cinatl, H. Doerr and A. Chandra, Anticancer Res., 22, 2657 (2002).

33. Scientific Committee on Health and Environmental Risks, Opinion on Classification of Musk Ketone, (SCHER) (2006).

34. L.D. Lehman-McKeeman, D. Caudill, J.D. Vassallo, R.E. Pearce, A. Madan and A. Parkinson, Toxicol. Lett., 111, 105 (1999).

35. European Commission, Summary Risk Assessment Report on (4'-tertButyl-2',6'-dimethyl-3',5'-dinitroacetophenone) Musk Ketone (2005); http://esis.jrc.ec.europa.eu.

36. S. Eisenhardt, B. Runnebaum, K. Bauer and I. Gerhard, Environ. Res., 87, 123 (2001).

37. N. Bitsch, C. Dudas, W. Körner, K. Failing, S. Biselli, G. Rimkus and H. Brunn, Arch. Environ. Contam. Toxicol., 43, 257 (2002).

38. L. Wollenberger, M. Breitholtz, K. Ole Kusk and B.-E. Bengtsson, Sci. Total Environ., 305, 53 (2003).

39. B. van der Burg, R. Schreurs, S. van der Linden, W. Seinen, A. Brouwer and E. Sonneveld, Int. J. Androl., 31, 188 (2008).

40. G. Carlsson and L. Norrgren, Arch. Environ. Contam. Toxicol., 46, 102 (2004).

41. European Commission, Summary Risk Assessment Report on $(1,3,4,6$, 7,8-Hexahydro-4,6,6,7,8,8-hexamethylcyclopenta-g-2-benzopyran) HHCB (2008): http://esis.jrc.ec.europa.eu.

42. P. Steinberg, T. Fischer, M. Arand, E. Park, I. Elmadfa, G. Rimkus, H. Brunn and H.-P. Dienes, Toxicol. Lett., 111, 151 (1999).

43. European Commission, Summary Risk Assessment Report 1-(5,6,7,8Tetrahydro-3,5,5,6,8,8-hexamethyl-2-naphthyl ethane-1-one) AHTN, (2008); http://esis.jrc.ec.europa.eu.

44. A. Covaci, Human Exposure and Health Risks to Emerging Organic Contaminants, In: Emerging Organic Contaminants and Human Health, Springer (2012).

45. OSPAR, OSPAR Background Document on Musk Xylene and Other Musks, OSPAR Commission (2004).

46. WHO, Biomonitoring of Human Milk for Persistent Organic Pollutants (POPs) (2009).

47. D. Costopoulou, I. Vassiliadou, A. Papadopoulos, V. Makropoulos and L. Leondiadis, Chemosphere, 65, 1462 (2006).

48. G.M. Solomon and P.M. Weiss, Environ. Health Perspect., 110, A339 (2002).

49. C.S. Kang, J.-H. Lee, S.-K. Kim, K.-T. Lee, J.S. Lee, P.S. Park, S.H. Yun, K. Kannan, Y.W. Yoo, J.Y. Ha and S.W. Lee, Chemosphere, 80, 116 (2010).

50. S. Lignell, P.O. Darnerud, M. Aune, S. Cnattingius, J. Hajslova, L. Setkova and A. Glynn, Environ. Sci. Technol., 42, 6743 (2008).

51. M. Schlumpf, K. Kypke, M. Wittassek, J. Angerer, H. Mascher, D. Mascher, C. Vökt, M. Birchler and W. Lichtensteiger, Chemosphere, 81, 1171 (2010).

52. H. Wang, J. Zhang, F. Gao, Y. Yang, H. Duan, Y. Wu, J.-D. Berset and B. Shao, J. Chromatogr. B, 879, 1861 (2011).

53. J. Yin, H. Wang, J. Zhang, N. Zhou, F. Gao, Y. Wu, J. Xiang and B. Shao, Chemosphere, 87, 1018 (2012).

54. X. Zhang, G. Liang, X. Zeng, J. Zhou, G. Sheng and J. Fu, J. Environ. Sci. (China), 23, 983 (2011). 